\title{
Легочный амилоидоз
}

\section{А.Ю.Третьяков ${ }^{1}$, С.П.Захарченко ${ }^{1}$, В.А.Третьякова ${ }^{2}$}

1 - Федеральное государственное автономное образовательное учреждение высшего образования «Белгородский государственный национальный исследовательский университет» Министерства образования и науки Российской Федерации: 308015, Белгород, ул. Победы, 85;

2 - Федеральное государственное автономное образовательное учреждение высшего образования «Российский университет дружбы народов»: 117198, Москва, ул. Миклухо-Маклая, 6

Информация об авторах

Третьяков Андрей Юрьевич - д. м. Н., профессор Медицинского института Федерального государственного автономного образовательного учреждения высшего образования «Белгородский государственный национальный исследовательский университет» Министерства образования и науки Российской Федерации; тел.: (4722) 30-12-11; e-mail: opensource2007@yandex.ru

Захарченко Светлана Петровна - к. м. н., старший научный сотрудник Медицинского института Федерального государственного автономного образовательного учреждения высшего образования «Белгородский государственный национальный исследовательский университет» Министерства образования и науки Российской Федерации; тел.: (4722) 30-12-11; e-mail: openbox.2013@yandex.ru

Третьякова Виктория Андреевна - клинический ординатор кафедры внутренних болезней с курсом кардиологии и функциональной диагностики Федерального государственного автономного образовательного учреждения высшего образования «Российский университет дружбы народов»; тел.: (495) 787-38-03; e-mail: Tretyakova.doc@yandex.ru

\section{Резюме}

Амилоидоз относится к классу орфанных заболеваний. Среди других систем организма с амилоидозом в наименьшей степени ассоциирована дыхательная система. Современные данные по проблеме легочного амилоидоза представлены на основе литературного обзора и авторского описания редкого примера альвеолярно-септальной формы поражения легких; рассмотрены вопросы клинической неоднородности пульмонологической патологии при системном и местном амилоидозе (AL - белок-предшественник - легкие цепи иммуноглобулинов, димер $\lambda$ и мономер $x$; AA - воспалительные острофазовые белки; ATTR - старческий и наследственный, белокпредшественник - транстиретин). Один из разделов посвящен патогенезу диффузного паренхиматозного (одностороннего и двустороннего), узлового и трахеобронхиального (с депозитами амилоида в проксимальных, средних или дистальных отделах бронхиального дерева) вариантов болезни, вовлечению в процесс внутригрудных лимфатических узлов (амилоидная аденопатия), плевры и диафрагмы, вопросам дифференциальной диагностики данных вариантов легочного амилоидоза.

Ключевые слова: $\mathrm{AL}-$-амилоидоз, диффузный альвеолярно-септальный легочный амилоидоз, узловой и трахеобронхиальный легочный амилоидоз.

Для цитирования: Третьяков А.Ю., Захарченко С.П., Третьякова В.А. Легочный амилоидоз. Пульмонология. 2018 ; 28 (1): 75-83. DOI: 10.18093/0869-0189-2018-28-1-75-83

\section{Pulmonary amyloidosis}

\author{
Andrey Yu. Tret'yakov', Svetlana P. Zakharchenko ${ }^{1}$, Viktoriya A. Tret'yakova ${ }^{2}$ \\ 1 - Federal Belgorod National Research University: ul. Pobedy 85, Belgorod, 308015, Russia; \\ 2 - The Peoples' Friendship University of Russia: ul. Miklukho-Maklaya 6, Moscow, 117198, Russia
}

Author information

Andrey Yu. Tret'yakov, Doctor of Medicine, Professor, Medical Institute, Federal Belgorod National Research University, Ministry of Education and Science of Russian Federation; tel.: (4722) 30-12-11; e-mail: opensource2007@yandex.ru

Svetlana P. Zakharchenko, Candidate of Medicine, Senior Researcher, Medical Institute, Federal Belgorod National Research University, Ministry of Education and Science of Russian Federation; tel.: (4722) 30-12-11; e-mail: openbox.2013@yandex.ru

Viktoriya A. Tret'yakova, Resident Physician, Department of Internal Medicine with the Course of Cardiology and Functional Diagnosis, The Peoples' Friendship University of Russia; tel.: (495) 787-38-03; e-mail: Tretyakova.doc@yandex.ru

\section{Abstract}

Amyloidosis is an orphan disease. Amyloidosis is uncommonly associated with respiratory disorders. The present article is a review of recently published data on pulmonary amyloidosis and a case report of alveolar and septal amyloid lung injury. Clinical heterogeneity of lung lesions in systemic and limited AL amyloidosis (precursor proteins are light chains of immunoglobulins, $\lambda$ dimer and $x$ monomer), AA amyloidosis (inflammatory acute-phase proteins), and ATTR amyloidosis (senile and inherited amyloidosis; precursor protein is transthyretin) have been discussed. One chart of the review has been devoted to the pathogenesis of diffuse parenchymatous (unilateral and bilateral) amyloidosis, nodular and tracheobronchial amyloidosis (with amyloid deposits in proximal, medium and distal airways, intrathoracic lymph node involvement (amyloid lymphadenopathy), amyloidosis of the pleura and the diaphragm, and differential diagnosis of these types of pulmonary amyloidosis.

Key words: AL amyloidosis, diffuse alveolar and septal pulmonary amyloidosis, nodular and tracheobronchial pulmonary amyloidosis.

For citation: Tret'yakov A.Yu., Zakharchenko S.P., Tret'yakova V.A. Pulmonary amyloidosis. Russian Pulmonology. 2018; 28 (1): 75-83 (in Russian). DOI: $10.18093 / 0869-0189-2018-28-1-75-83$

Амилоидоз - редкая (орфанная) патология. На сегодняшний день в европейской популяции регистрация болезни составляет всего от 3 до 14 новых случаев в год на 1 млн населения [1-3]. Данные же о вероятности поражения легких при амилоидозе раз- личаются более существенно - от 31 до $88 \%$ [4-6]. Такой почти троекратный разброс показателя определен в основном материалом, используемым для оценки: в одних исследованиях амилоидоз - это прижизненная клиническая находка, в других - заклю- 
чение аутопсии. По этой причине реальная картина частоты респираторной патологии при амилоидозе на сегодняшний день отсутствует [7].

Клиническая неоднородность легочного амилоидоза определяется 3 основными условиями: во-первых, пульмонологические особенности - способность формировать фактор многообразия типов амилоидного фибриллярного белка (специфика белка-предшественника); во-вторых, свойство самого амилоидоза быть системной патологией или сугубо местным (локальным) расстройством - последнее, в свою очередь, увязано с тем, является ли он врожденным (наследственным) или приобретенным процессом. Третья причина такой разнородности место преимущественного отложения амилоидных масс в легочной ткани, формирующее конкретное клиническое выражение заболевания.

Согласно последним рекомендациям Комитета по номенклатуре Международного общества амилоидоза (ISA, 2016), болезнь у человека формируют 36 внеклеточных фибриллярных белков, 15 из них определяют системный вариант заболевания, 19 локальный, 2 - AL и амилоидоз, ассоциированный с отложением тяжелых цепей иммуноглобулинов $(\mathrm{Ig}),-$ смешанную (локальную и системную) формы процесса $[8,9]$. В соответствии с указанной классификацией список системных вариантов чаще составляют наследственные формы, тогда как местный амилоидоз - в основном приобретенная патология. В свою очередь, из данного обширного перечня в клинической практике наиболее распространенными по-прежнему остаются системный AL (белок-предшественник - легкие цепи иммуноглобулинов, димер $\lambda$ и мономер $x$ ), АА (сывороточный амилоид A), ATTR (старческий и наследственный, белок-предшественник - транстиретин) и $\mathrm{A} \beta_{2} \mathrm{M}$ (белок-предшественник - $\beta_{2}$-микроглобулин) амилоидоз, часто сопряженный с процедурой гемодиализа [8]. Нетрудно увидеть, что правила обозначения типа амилоидоза строятся из указания фибриллярного белка амилоида (литера А), далее называется белок-предшественник и конкретизируется клиническая форма болезни.

Понятия «локальный» (местный) и «системный» амилоидоз главным дополнением предполагают, помимо факта вовлечения соответственно одного или сразу нескольких органов, признак совпадения места продукции белка-предшественника и отложения амилоидных фибрилл - для локального варианта (амилоидоз in situ) и пространственную отдаленность данных процессов, когда речь идет о системном амилоидозе. В последнем случае всегда соблюдается правило последовательности событий синтеза исходного белка, например в костном мозге или печени, поступление его растворимой формы в плазму (системный кровоток) и лишь затем - отложение фибрилл в конкретных органах $[10,11]$.

Наиболее часто легочный амилоидоз встречается при AL-, AA- и наследственном (обусловленным мутацией гена транстиретина) ATTR-вариантах [7]. B этом списке на AL-тип приходится самое большое количество пульмонологических расстройств 63-80\% [12, 13]. По этой причине здесь требуется одно пояснение. Рассматривая системный AL-aмилоидоз, необходимо различать его не только как первичную (самостоятельную) форму, но и как состояние, дополняющее главные плазмоклеточные дискразии (множественную миелому (ММ), моноклональную гаммапатию неопределенного значения). ММ - заболевание, встречающееся на порядок чаще, чем амилоидоз. К примеру, средняя частота присутствия клинически демонстративного амилоидоза при ММ составляет 12-20\%; примерно у 30-35 \% больных ММ с отсутствием явных симптомов амилоидоза возможно обнаружить амилоидные отложения при аспирации подкожного жирового слоя, биопсии костного мозга, печени и почек [14, 15]. В то же время недавние попытки некоторых исследователей увязать развитие AL-амилоидоза преимущественно с миеломной болезнью, увеличивая тем самым число подобной ассоциации до 57-80 \%, встретили аргументированное неприятие, и статус данной формы амилоидоза как самостоятельной болезни остался прежним $[16,17]$.

Что касается моноклональной гаммапатии неопределенного значения (MGUS), то это заболевание неоднородно, и в современной классификации подразделяется на 3 клинических подтипа. Каждый из них имеет свой возможный специфический путь трансформации, где лишь типы не-IgM MGUS и MGUS с продукцией легких цепей способны эволюционировать до MM- или AL-амилоидоза (скорость прогрессии - около 1 \% в год) [18], причем среди пациентов с MGUS (исключая тип MGUS с синтезом легких цепей) вероятность последующего AL-амилоидоза составляет примерно 10 \% всех эволюционных событий [19, 20].

Представленные клинические сочетания AL-амилоидоз-миелома, AL-амилоидоз-MGUS свидетельствуют о патогенетической общности этих трех заболеваний. Например, у них присутствуют единые цитогенетические аномалии, когда гипердиплоидия (наличие > 46 хромосом) встречается у $50 \%$ больных MM, 30 \% - MGUS и в 10-11\% случаев $\mathrm{AL}$-амилоидоза. Тесно связанное с гиперплоидией явление трисомии (не парное, но утроенное состояние хромосом), свойственное ММ, обнаруживается и при AL-амилоидозе [21]. Транслокация 11;14 (обмен сегментов между 11-й и 14-й хромосомами) при ММ бывает распространена до $80 \%$, а при $\mathrm{AL}-$-амилоидозе продемонстрирована в 30-50 \% примеров [22]. Показатель нагрузки плазматическими клетками костного мозга для 60 \% больных AL-амилоидозом невелик (около 7 \%), однако почти в каждом 5-м случае имеется рост этого значения > $20 \%$, как при ММ [14, 23].

Являясь самостоятельным заболеванием, AL-амилоидоз определен построением фибрилл, преимущественно из N-концевых аминокислотных остатков вариабельных областей легких цепей (VL) Ig [14]. B отличие от большинства других дискразий плазматических клеток, $\lambda$-изотип составляет $75 \%$ ами- 
лоидогенных легких цепей, кодируемых на $60 \%$ всего тремя V $\lambda$ генами: IGLV2-14 ( $\lambda$ II), IGVL6-57 $(\lambda$ VI) и IGVL3-1 ( $\lambda$ III) $[24,25]$.

Второе место в формировании легочного амилоидоза занимает АА-вариант. Отложения здесь состоят в основном из сывороточного амилоидного белка A (SAA), синтезируемого в форме предшественника гепатоцитами в ответ на транскрипционные стимулы от различных провоспалительных цитокинов: интерлейкинов- $1,-6$, фактора некроза опухоли- $\alpha$ (по этой причине прежнее название системного АА-амилоидоза - вторичный амилоидоз, т. е. зависимый от иной хронической воспалительной патологии процесс). На сегодняшний день известно по крайней мере 5 аллельных вариантов сывороточного амилоидного белка А, обладающих неодинаковой амилоидогенностью. Причем амилоидные фибриллы создаются не только из них, но включают еще и сывороточный амилоидный Р-компонент, гепарансульфат и гликозаминогликан [26].

Изолированно легочная ткань при амилоидозе вовлекается в патологический процесс очень редко, а сам легочный амилоидоз - как системный, так и местный - существует в одной из 3 клинических форм: диффузной альвеолярно-септальной (односторонний или двусторонний паренхиматозный амилоидоз), узловой и трахеобронхиальной. Кроме того, возможно патологическое вовлечение еще 3 дополнительных анатомических структур - внутригрудных лимфатических узлов (амилоидная аденопатия), плевры и очень редко - диафрагмы. Альвеолярно-септальная форма, при которой амилоидные отложения сосредоточены в интерстиции (между сосудистым эндотелием и альвеолярным эпителием), наиболее типична для AL-амилоидоза, но возможна при любом ином системном варианте, например старческом и наследственном ATTR [27, 28], причем старческий тип прогрессивно повышает свою значимость после 80 лет: по результатам анализа 340 вскрытий выявлены легочные сосудистые или альвеолярно-септальные амилоидные отложения у $2 \%$ умерших моложе 80 лет, у $10 \%$ - в возрасте от 80 до 84 лет и у $20 \%$ - старше 85 лет [29].

Главным сценарием узловой формы служит локальный AL- или AL/AH- (отложение и легких, и тяжелых цепей Ig) амилоидоз, реже - системный $\mathrm{AL}$, локальный AA, локальный ATTR дикого типа (старческий) и локальный A $32 \mathrm{M} / \mathrm{AL}$ (совместное отложение $\beta_{2}$-микроглобулина и легких цепей $\mathrm{Ig}$ ). Причем при узловой форме основным белкомпредшественником выступает не $\lambda$, а $x$-изотип Ig, здесь его доля составляет около 70 \%. Трахеобронхиальный амилоидоз имеет преимущественно локальный AL-механизм формирования с возможностью развития также при системном AL и AA типах [30-33].

M.W.Pitz et al. (2006) на основе литературного анализа 195 случаев легочного амилоидоза указывают, что самой частой формой служит паренхиматозный (альвеолярно-септальный) вариант; на его долю приходится 53,8 \% случаев. Если проводится анализ только вариантов системного амилоидоза, тогда регистрация ситуаций с альвеолярно-септальными амилоидными депозитами возрастает до $88 \%$ [6]. Наоборот, в исследовании E.A.Geusens et al. (1997) более распространенным считается трахеобронхиальный тип [34].

Такая разница значений диагностики отдельных типов болезни вполне объяснима. Все зависит от того, о каком конкретно амилоидозе идет речь, локальном или системном; если трахеобронхиальный (как и узловой) тип возможен и при системном, и при местном амилоидозе, то диффузный паренхиматозный вариант отложения амилоидных масс очень трудно увязать с локальной (легочной) продукцией амилоидогенных субстанций. Этот тип почти всегда будет следствием системного амилоидоза, а как проявление локальной формы - редчайшим (Berk J.L. et al., 2002). Оценка только случаев местного амилоидоза (126 находок) дает следующую картину: 53 \% составляет трахеобронхиальный вариант, $44 \%$ - узловой и лишь $3 \%$ - паренхиматозный [12, 31].

Трахеобронхиальный амилоидоз, подразделяясь на проксимальную форму, поражение в средних и дистальных отделах бронхиального дерева, клинически наиболее выразителен и сопровождается стридором, одышкой (в результате бронхообструктивного синдрома), появлением свистящих хрипов, кашлем, кровохарканьем, снижением скоростных показателей функции внешнего дыхания [35, 36]. Причем функциональные тесты чаще нарушаются в ситуации обструкции проксимальных отделов, тогда как локализация амилоидных отложений в дистальных участках респираторного тракта мало влияет на характеристики воздушного потока [30]. Оссификация амилоидных масс формирует остеопластическую трахеобронхопатию, а отдельный, т. н. опухолевый вариант трахебронхиального амилоидоза, способен имитировать бронхогенную карциному [28, 37, 38]. При обструктивном процессе с сегментарной или долевой гиповентиляцией (ателектазом) повышается вероятность повторных пневмоний и формирования бронхоэктазов; дополнительно возможно развитие обструктивной «клапанной» (сегментарной или долевой) гиперинфляции [28, 31].

Альвеолярно-септальная и узловая формы легочного амилоидоза даже при обширном распространении у большей части больных могут не иметь каких-либо специфических пульмонологических симптомов, обнаруживаясь случайно при рентгенологическом исследовании или на аутопсии. К примеру, у 64 \% лиц с массивным паренхиматозным вариантом болезни полностью отсутствовали клинические признаки [39]. Однако возможны рецидивирующий кашель, кровохарканье, повторные пневмонии, одышка [35, 40]. Кровохарканье в ситуации легочного амилоидоза объясняется спонтанным расслаиванием легочных артерий малого и среднего калибра, в стенках которых присутствуют депозиты амилоида; кроме этого, причиной кровохарканья 
может быть инфаркт легких в результате массивного тромбоза нижней полой вены как следствие ее внешней компрессии амилоидными массами [40].

Диффузная альвеолярно-септальная (паренхиматозная) и узловая формы чаще встречаются у лиц старше 60 лет. В первом случае, как уже указано, имеет место распространенная инфильтрация альвеолярных перегородок, паравазальных и перибронхиальных зон. При нодулярном варианте обнаруживаются одиночные или множественные узелки (амилоидомы) различающиеся по размеру (от малых - в несколько миллиметров, до значительных, достигающих 15 см) и форме, с медленным многолетним характером роста; в 50 \% случаев они могут быть оссифицированы [31].

Необходимо понимать, что патология легких в прогнозе при системном AL-амилоидозе только у 1 из 12 больных приобретает доминирующую роль, а как фактор танатогенеза выступает лишь в $10 \%$ таких ситуаций [39]. Это обусловлено частым присутствием при легочном поражении еще и сердечного амилоидоза. Согласно утвердившемуся мнению, легочный амилоидоз является всего-навсего маркером амилоидной инфильтрации миокарда, которая в умеренной и тяжелой форме свойственна $92 \%$ больных с AL-формой [6, 39]. Иначе говоря, сердечный амилоидоз далеко не всегда допускает аналогичные изменения в легких, но факт поражения последних у подавляющего большинства пациентов служит указанием за наличие амилоидной кардиомиопатии [6].

Частота поражения внутригрудных лимфатических узлов при амилоидозе точно не определена, известно только, что они вовлекаются реже, чем экстраторакальные, и вместе с ними встречаются в пределах 8 \% для системной AL-формы [39]. При изолированной медиастенальной, паратрахеальной амилоидной лимфаденопатии требуется исключить лимфогранулематоз и саркоидоз. Последний при длительном течении сам может явиться источником системного АА-амилоидоза и соответствующего поражения легких.

Реакция плевры с рецидивирующим выпотом при амилоидозе - явление преимущественно вторичное и связано либо с застойной сердечной недостаточностью на фоне сопутствующей амилоидной кардиомиопатии, либо с нефротическим синдромом как следствием амилоидной нефропатии. Иногда обширное поражение плевры амилоидными массами определяет развитие хилоторакса [39].

Амилоидная инфильтрация диафрагмы встречается очень редко и в тяжелых случаях существенно нарушает механику дыхания. Прижизненная неинвазивная оценка таких расстройств возможна при диафрагмальной флюороскопии (sniff test) [41].

В соответствии с конкретной формой легочного амилоидоза при AL-типе рентгенологическая картина бывает представлена одним из следующих вариантов: диффузным ретикулярным (около 33 \%), ретикулонодулярным (около 23 \%) или нодулярным. Кроме того, возможен изолированный рецидиви- рующий односторонний или двусторонний плевральный выпот (примерно у 29 \%), утолщение плевры (1-3 \%) и увеличение внутригрудных лимфатических узлов. В случае сопутствующего поражения сердца к этим симптомам добавляются признаки легочной венозной гипертензии - линейные тени Керли В и «цефализация» легочного рисунка, когда сосуды верхних отделов легочных полей более выражены, чем в базальных участках. При компьютерной томографии выявляется утолщение междольковых перегородок, альвеолярная непрозрачность, узелки с субплевральным преобладанием, признаки локального и диффузного стенозирования трахеи и бронхиальной обструкции, постстенотические ателектазы, утолщение стенок дыхательных путей с наличием в их просветах узлов, кальцинатов [4, 42]. В отдельных ситуациях, когда амилоидоз легких был патологоанатомическим диагнозом, при жизни рентгенограмма оставалась либо нормальной, либо отмечались «неспецифические» изменения [39].

Эндоскопическое исследование показательно лишь при трахеобронхиальной форме. Здесь бронхоскопическая картина соответствует одному из двух типов отложения амилоида: узловому (унифокальному) и диффузному подслизистому.

Во всех случаях окончательная диагностика амилоидоза, конкретизация варианта легочной патологии и типа амилоидного белка строится на морфологической оценке. Амилоидный материал традиционно идентифицируется на основе его метахроматических свойств с анилиновыми красителями, в первую очередь конго красным. Такой оптический эффект обусловлен пространственной ориентацией молекул красителя между амилоидными фибриллами со способностью их отражать и поглощать свет. Обязательным условием исследования является оценка материала в поляризованном свете, где амилоид приобретает зеленое свечение. Однако по мнению A.J.Howie (2010), такое классическое яблочно-зеленое свечение можно увидеть только в идеальных условиях, в связи с чем другие хроматические комбинации, такие как зелено-желтое, сине-желтое и красно-зеленое, будут также диагностически состоятельными [43]. Иммуногистохимическое окрашивание с использованием антител против $\lambda$, или $x$-цепей Ig, SAA или транстиретина позволяет окончательно разобраться в типе амилоидоза и выработать адекватную лечебную программу.

Дифференциальная диагностика легочного амилоидоза с другими заболеваниями проводится с учетом одной из 3 клинических форм. Так, при узловой форме требуется исключение в основном первичной или метастатической неоплазии, гиалинизирующих легочных гранулем и иных нозологий, хорошо известного списка очаговых / нодулярных поражений легких. Диффузный альвеолярно-септальный амилоидоз предполагает исключение туберкулеза, бронхоальвеолярной карциномы, профессиональных заболеваний и изменений легких при коллагенозах, лекарственных и идиопатических интерстициальных пневмопатий. Течение трахеобронхиального 
амилоидоза может напоминать клиническую картину бронхиальной астмы, гранулематоза с полиангиитом, трахеобронхиального папилломатоза, остеохондропластической трахеопатии, центрального рака и нейроэндокринной опухоли бронхов.

Специфическая терапия амилоидоза легких возможна в основном при системном AL-варианте (системные глюкокортикостероиды, мелфолан). В остальном, кроме хирургической коррекции, используется симптоматическая терапия, направленная на снижение выраженности дыхательной и хронической сердечной недостаточности, борьбе с инфекционными бронхолегочными осложнениями.

\section{Клиническое наблюдение}

Больной Я. 74 лет госпитализирован 26.10 .16 с жалобами на малопродуктивный кашель с мокротой слизистого характера, больше в утренние часы, одышку смешанного типа при ходьбе, отеки стоп и лодыжек. Пациент - городской житель, образование среднее техническое, в течение жизни работал наладчиком, профессиональных вредностей не отмечает. Не курит, алкоголем не злоупотребляет. О заболеваниях родителей сообщить ничего не смог (отец и мать умерли в возрасте старше 60 лет), есть сын 42 лет, здоров. Из перенесенных заболеваний: детские инфекции, в возрасте 11 лет перенес гепатит А, в 20 лет - аппендэктомию, в 34 года язвенную болезнь желудка, эндоскопическое исследование 5-летней давности свидетельствовало о рубце на передней стенке антрального отдела. Аллергическая реакция в виде уртикарной сыпи на пчелиный яд. В анамнезе заболевания - указание на онемение пальцев рук в холодное время года в течение последних 3 лет. Считает себя больным на протяжении 1,5 года, когда появился малопродуктивнй кашель, одышка, боль в нижней половине грудной клетки при глубоком вдохе и кашле, отеки ног. Лечился в пульмонологическом отделении по поводу предполагаемой двусторонней пневмонии с локализацией в базальных отделах. В связи с отсутствием клиническо-рентгенологической динамики на фоне 3-недельного курса антимикробной терапии направлен во фтизиатрический стационар; после месячного обследования и отрицательных результатов диагностики микобактерий при помощи полимеразной цепной реакции в мокроте и крови диагноз туберкулезного процесса исключен. В течение 1 мес. (сентябрь 2016) состояние постепенно ухудшалось: усилился кашель, боль в нижних отделах грудной клетки, стала прогрессировать одышка, появились приступы удушья в ночное время, увеличились отеки нижних конечностей.

При поступлении: состояние средней тяжести, больной сидит, температура тела $36,5^{\circ} \mathrm{C}$; рост - $166 \mathrm{~cm}$, масса тела - 63 кг. Кожные покровы бледные, обычной влажности, тургор сохранен, отеки стоп и нижней трети голеней. Периферические лимфатические узлы не увеличены, мягкой консистенции, безболезненные, не спаяны между собой и с соединительной тканью. Мышечная система развита нормально, безболезненна, тонус сохранен, двигательная активность не нарушена. Крупные и мелкие суставы нормальной конфигурации, при пальпации безболезненные, движения в суставах в полном объеме. Щитовидная железа пальпаторно не увеличена. Дыхание через нос свободное, форма грудной клетки цилиндрическая. При перкуссии легких отмечается притупление перкуторного звука в базальных отделах с обеих сторон, при аускультации дыхание жесткое, в базальных отделах ослабленное, хрипов нет, шума трения плевры нет. Частота дыхательных движений в положении сидя - 21 в минуту, сатурация кислородом $-83 \%$. Тоны сердца ритмичные, приглушены, частота сердечных сокращений - 76 в минуту. Короткий систолический шум над верхушкой. Артериальное давление на обеих руках 110 / 70 мм рт. ст. Язык влажный, чистый, глотание свободное. Живот мягкий, умеренно болезненный в правом подреберье, печень не пальпируется, размеры по Курлову $-10 \times 9 \times 8$ см, селезенка не пальпируется, размер селезенки $-7 \times 5$ см. Симптом поколачивания отрицательный с обеих сторон, почки не пальпируются. Мочеполовая система без особенностей. Неврологический статус без очаговой и менингеальной симптоматики.
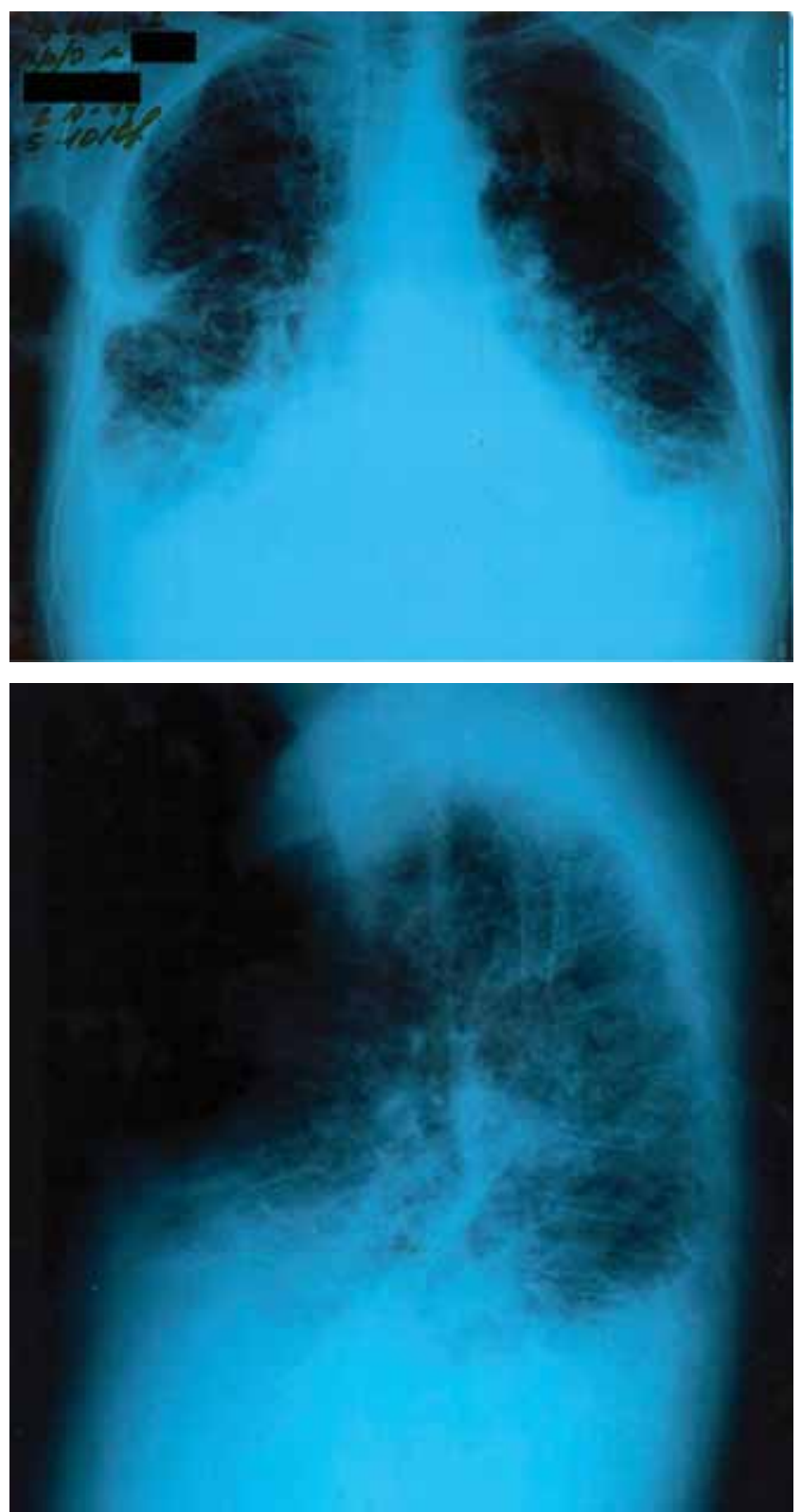

Рис. 1. Рентгенограмма органов грудной клетки больного Я. (описание см. в тексте)

Figure 1. Chest X-ray of the patient Ya. (see comments in the article)

Рентгенография органов грудной клетки (рис. 1): грудная клетка правильной формы. С обеих сторон, преимущественно в средних и нижних легочных полях отмечаются тени линейного характера за счет обогащения сосудистого рисунка, в базальных отделах обоих легких - интерстициальный фиброз, корни легких расширены, бесструктурные, боковые синусы завуалированы за счет жидкости в плевральных полостях, в проекции правой междолевой щели - небольшое количество осумкованной жидкости, диафрагма четко не дифференцируется, сердце расширено в поперечнике, средостение не смещено.

Результаты компьютерной томографии (КТ) органов грудной клетки (рис. 2): в обеих плевральных полостях определяется свободная жидкость, отграниченное скопление жидкости также визуализируется по косой щели правого легкого, базальные отделы легких коллабированы, с обеих сторон отмечаются плевральные наслоения, воздушность легочной паренхимы неоднородная за счет участков уплотнения легочной ткани по типу «матового стекла», отмечается выраженное утолщение междольковых перегородок и внутридолькового интерстиция, сосудистый рисунок усилен, корни легких расширены, средостение структурно, не смещено, трахея - без особенностей, бронхи I-III порядка проходимы, лимфатические узлы средостения (паратрахеальные и бифуркационные) увеличены; сердце расположено обычно, 

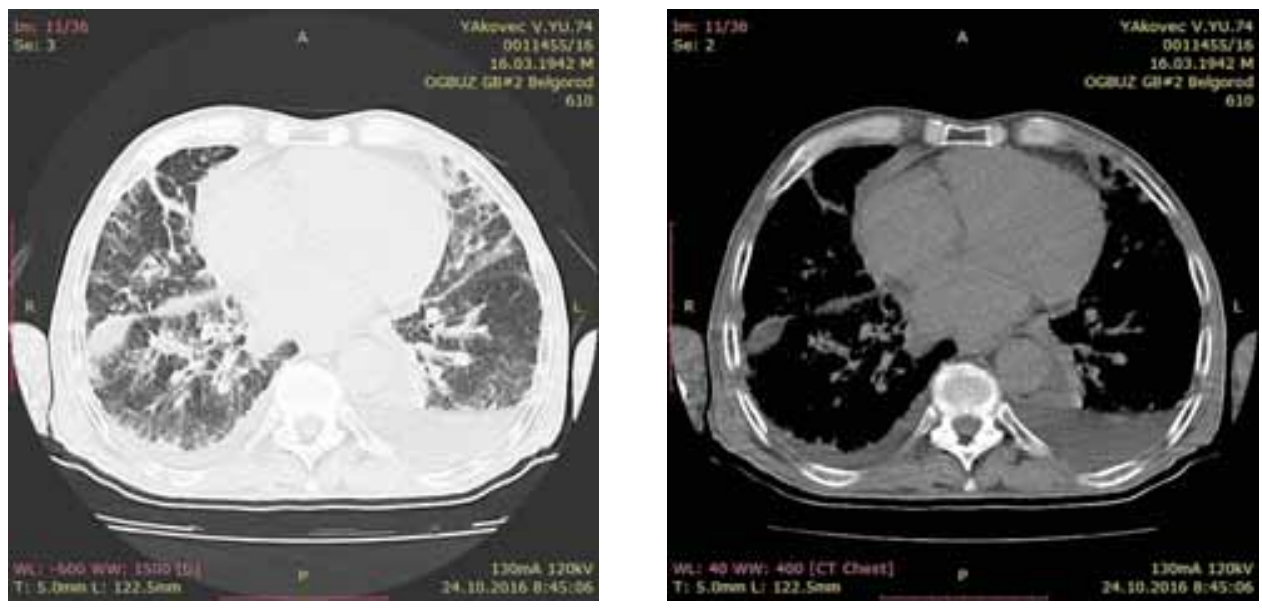

Рис. 2. Компьютерная томограмма органов грудной клетки больного Я. (описание см. в тексте)

Figure 2. Computed tomogram of the patient Ya. (see comments in the article)

резко увеличено в размерах за счет расширения всех камер, в полости перикарда определяется небольшое количество свободной жидкости.

Фибробронхоскопия: катаральный бронхит. Функция внешнего дыхания: умеренная бронхиальная обструкция, рестриктивные нарушения III степени. Электрокардиография: синусовая тахикардия, отклонение электрической оси влево, снижение вольтажа зубцов в стандартных и грудных отведениях, неполная блокада правой ножки пучка Гиса. Эхокардиографическое исследование: толщина межжелудочковой перегородки - 1,6 см; толщина задней стенки левого желудочка (ЛЖ) - 1,5 см; конечный диастолический размер (КДР) ЛЖ - 4,0 см; КДР левого предсердия 4,8 × 6,0 см; КДР правого желудочка - 3,6 см; КДР правого предсердия - 5,8 × 6,7; свободная стенка правого желудочка 0,7 см; диффузная гипокинезия ЛЖ; фракция выброса - 52 \%; кальциноз створок аортального, митрального клапанов, недостаточность аортального клапана с регургитацией I степени, недостаточность митрального клапана с регургитацией II степени недостаточность трикуспидального клапана с регургитацией II степени, рестриктивный тип диастолической дисфункции ЛЖ (однофазный поток Е - 33 см / с), небольшое количество жидкости в перикарде. Рентгенография костей свода черепа и костей таза: без патологических изменений. Ультразвуковое исследование брюшной полости, забрюшинного пространства: печень не увеличена (длина правой доли $-12,2$ см, левой $-6,4$ см), эхоструктура печени диффузно неоднородна, желчный пузырь $11,8 \times 3,1$ см, стенки - до 3 мм; поджелудочная железа - 2,6 × $1,8 \times 2,4$ см, контуры четкие ровные, эхогенность повышена, эхоструктура диффузно неоднородна; селезенка не увеличена; правая почка - 10,9 × 4,2 см, паренхима -15 мм, левая почка $-10,1 \times$ 4,5 см, паренхима - 14 мм, кисты синуса правой почки; небольшое количество свободной жидкости в брюшной полости и полости малого таза. Стернальная пункция: количество плазматических клеток $-4,3 \%$. Общий анализ крови: эритроциты $-4,12 \times$ $10^{12}$ / л; гемоглобин - 124 г / л; лейкоциты - 4,8 × 109 / л; гранулоциты - 80,8 \%; лимфоциты - $15,4 \%$; моноциты - 3,8 \%; $\mathrm{CO}$ - 22 мм / ч. Общий анализ мочи: цвет желтый, $\mathrm{pH}-4,5$; плотность - 1,012; белок - отсутствует; эпителиальные клетки 1-2 в поле зрения (п. 3.); лейкоциты -5 в п. 3.; эритроциты -0 Биохимические анализы крови: общий белок - 50,8 г / л; билирубин - 11,1 мкМ / л; креатинин - 59,2 мкМ / л; мочевина 7,7 мМ / л; холестерин - 5,63 мМ / л; глюкоза - 5,3 мМ / л; аспартатаминотрансфераза - 21,5 Ед / л; аланинаминотрансфераза - 17,4 Ед / л; $\mathrm{Na}-133,5$ мМ / л; К - 5,03 мМ / л; витамин $\mathrm{B}_{12}-848$ пг / мл (N 190-663 нг / мл); сывороточное железо 11,0 мкМ / л; общий кальций сыворотки крови - 2,51 мМ / л. Экспресс-тест на тропонин I - отрицательный. Тесты на ВИЧ, RW, HbsAg и AntiHCV - отрицательные. Троекратный анализ мокроты на микобактерии туберкулеза и иные кислотоустойчивые микроорганизмы - отрицательный результат. Для конкретизации варианта поражения легких выполнена диагностическая торакотомия и биопсия легочной ткани. Результаты гистологического исследования (рис. 3): диффузно-очаговые отложения конго-позитивных аморфных масс в межальвеолярных перегородках и периваскулярных зонах. При иммуногистохимическом окрашивании, выполненном с помощью панели антител против
4 основных белков амилоидных фибрилл, показана сильная диффузная иммунореактивность к легким цепям иммуноглобулинов $(\lambda$-тип).

В дальнейшем использована симптоматическая терапия лазолван 120 мг в сутки, лечение сердечной недостаточности (инфузия фуросемида 40 мг в сутки № 17; диувер 5 мг в сутки № 4; верошпирон 100 мг в сутки № 21; эналаприл 2,5 мг в сутки № 21), гепарин 10 тыс. Ед в сутки № 10, кислородная терапия. После улучшения состояния направлен в Клинику нефрологии, внутренних и профессиональных болезней им. Е.М.Тареева для проведения специфической терапии AL-амилоидоза.

\section{Заключение}

По сравнению с другими системами человеческого организма дыхательная система существенно реже оказывается вовлеченной в патологический процесс при амилоидозе. Существование 3 различных и, повидимому, взаимоисключающих клинических форм легочного амилоидоза (диффузной альвеолярно-септальной, узловой и трахеобронхиальной) основано на специфике механизмов локального или системного вариантов болезни и уникальных свойствах белка-предшественника (или белков-предшественников) амилоида. Амилоидную природу поражения легких всегда необходимо исключать, когда имеет место нетипичное течение отдельных пульмонологических нозологий.

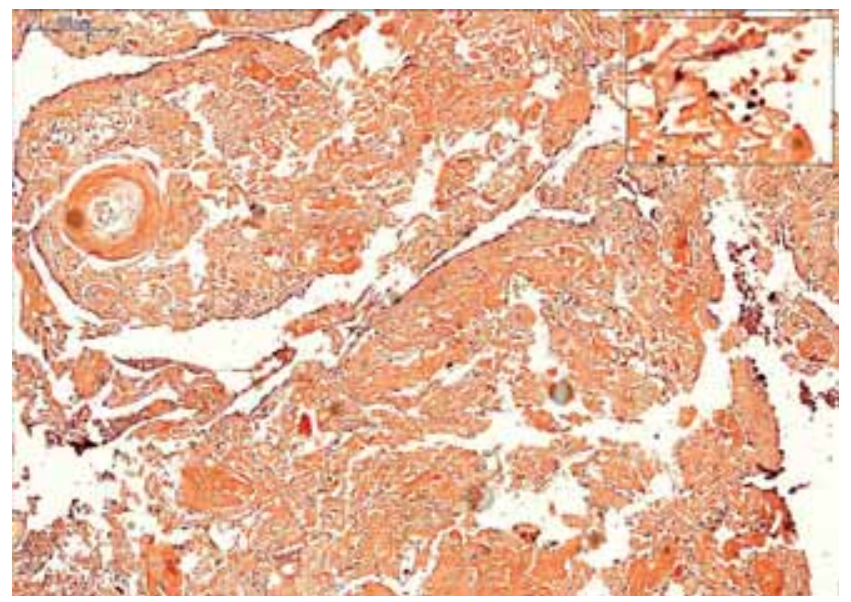

Рис. 3. Гистологическое исследование ткани легкого больного Я. депозиты амилоида в стенках кровеносных сосудов и в легочном интерстиции

Figure 3. Histological examination of lung tissue of the patient Ya.: amyloid deposits in vascular walls and pulmonary interstitium 
Конфликт интересов

Конфликт интересов авторами не заявлен.

Conflict of interest

The authors declare no conflict of interest.

\section{Литература}

1. Рамеев В.В., Козловская Л.В. Амилоидоз: современные методы диагностики и лечения. Эффективная фармакотерапия. 2012; (44): 6-15.

2. Pinney J.H., Smith C.J., Taube J.B. et al. Systemic amyloidosis in England: an epidemiological study. Br. J. Haematol. 2013; 161 (4): 525-532. DOI: 10.1111/bjh.12286.

3. Лысенко Л.В., Рамеев В.В. Национальные клинические рекомендации «Диагностика и лечение АAи AL-амилоидоза». М.; 2014. Доступно на: https://freedocs.xyz/view-docs.php?pdf $=456688967$

4. Urban B.A., Fishman E.K., Goldman S.M. et al. CT evaluation of amyloidosis: spectrum of disease. Radiographics. 1993; 13 (6): 1295-1308. DOI: 10.1148/radiographics. 13.6.8290725.

5. Brown K., Mund D.F., Aberle D.R. et al. Intrathoracic calcifications: radiographic features and differential diagnoses. Radiographics. 1994; 14 (6): 1247-1261. DOI: 10.1148/radiographics.14.6.7855339.

6. Smith R.R., Hutchins G.M., Moore G.W., Humphrey R.L. Type and distribution of pulmonary parenchymal and vascular amyloid. Correlation with cardiac amyloidosis. Am. J. Med. 1979; 66 (1): 96-104. DOI: 10.1016/0002-9343(79) 90488-1.

7. Scala R., Maccari U., Madioni C. et al. Amyloidosis involving the respiratory system: 5 -ear's experience of a multi-disciplinary group's activity. Ann. Thorac. Med. 2015; 10 (3): 212-216. DOI: 10.4103/1817-1737.157290.

8. Sipe J.D., Benson M.D., Buxbaum J.N. et al. Amyloid fibril proteins and amyloidosis: chemical identification and clinical classification International Society of Amyloidosis 2016 Nomenclature Guidelines. Amyloid. 2016; 23 (4): 209-213. DOI: 10.1080/13506129.2016.1257986.

9. Мухин Н.А., ред. Нефрология. Национальное руководство. М.: ГЭОТАР-Медиа; 2009.

10. Merlini G., Westermark P. The systemic amyloidoses: clearer understanding of the molecular mechanisms offers hope for more effective therapies. J. Int. Med. 2004; 255 (2): 159-178. DOI: 10.1046/j.1365-2796.2003.01262.x.

11. Merlini G., Seldin D.C., Gertz M.A. Amyloidosis: pathogenesis and new therapeutic options. J. Clin. Oncol. 2011; 29 (14): 1924-1933. DOI: 10.1200/jco.2010.32.2271.

12. Thompson P.J., Citron K.M. Amyloid and lower respiratory the tract. Thorax. 1983; 38 (2): 84-87.

13. Hui A.N., Koss M.N., Hochholzer L., Wehunt W.D. Amyloidosis presenting in the lower respiratory tract. Clinicopathologic, radiologic, immunohistochemical, and histochemical studies on 48 cases. Arch. Pathol. Lab. Med. 1986; 110 (3): 212-218.

14. Müller A.M., Geibel A., Neumann H.P.H. et al. Primary (AL) amyloidosis in plasma cell disorders. Oncologist. 2006; 11 (7): 824-830. DOI: 10.1634/theoncologist.11-7-824.

15. Bahlis N.J., Lazarus H.M. Multiple myeloma-associated AL amyloidosis: is a distinctive therapeutic approach warranted? Bone Marrow Transplant. 2006; 38 (1): 7-15. DOI: 10.1038/sj.bmt.1705395.

16. Dinner S., Witteles W., Witteles R. et al. The prognostic value of diagnosing concurrent multiple myeloma in immunoglobulin light chain amyloidosis. Br. J. Haematol. 2013; 161 (3): 367-372. DOI: 10.1111/bjh.12269.
17. Falk R.H. AL amyloidosis or multiple myeloma? An important distinction. Br. J. Haematol. 2014; 164 (5): 748-749. DOI: 10.1111/bjh.12677.

18. Merlini G., Palladini G. Differential diagnosis of monoclonal gammopathy of undetermined significance. Hematology Am. Soc. Hematol. Educ. Program. 2012; 2012: 595-603. DOI: 10.1182/asheducation-2012.1.595.

19. Kyle R.A., Therneau T.M., Rajkumar S.V. et al. Long-term follow-up of 241 patients with monoclonal gammopathy of undetermined significance: the original Mayo Clinic series 25 years later. Mayo Clin. Proc. 2004; 79 (7): 859-866. DOI: 10.4065/79.7.859.

20. Kyle R.A., Therneau T.M., Rajkumar S.V. et al. A longterm study of prognosis in monoclonal gammopathy of undetermined significance. N. Eng. J. Med. 2002; 346 (8): 564-569. DOI: 10.1056/nejmoa01133202.

21. Warsame R., Kumar S.K., Gertz M.A. et al. Abnormal FISH in patients with immunoglobulin light chain amyloidosis is a risk factor for cardiac involvement and for death. Blood Cancer J. 2015; 5: e310. DOI: 10.1038/bcj.2015.34.

22. Suzuki K. Diagnosis and treatment of multiple myeloma and AL amyloidosis with focus on improvement of renal lesion. Clin. Exp. Nephrol. 2012; 16 (5): 659-671. DOI: 10.1007/s10157-012-0684-5.

23. Ramirez-Alvarado M., Ward C.J., Huang B.Q. et al. Differences in immunoglobulin light chain species found in urinary exosomes in light chain amyloidosis (Al). PLoS One. 2012; 7 (6): e38061. DOI: 10.1371/journal.pone.0038061.

24. Comenzo R.L., Zhang Y., Martinez C. et al. The tropism of organ involvement in primary systemic amyloidosis: contributions of $\operatorname{Ig} \mathrm{V}(\mathrm{L})$ germ line gene use and clonal plasma cell burden. Blood. 2001; 98 (3): 714-720. DOI: 10.1182/ blood.v98.3.714.

25. Perfetti V., Casarini S., Palladini G. et al. Analysis of V $\lambda-J \lambda$ expression in plasma cells from primary (AL) amyloidosis and normal bone marrow identifies $3 r(\lambda I I I)$ as a new amyloid-associated germline gene segment. Blood. 2002; 100 (3): 948-953. DOI: 10.1182/blood-2002-01-0114.

26. Real de Asúa D., Costa R., Galván J.M. et al. Systemic AA amyloidosis: epidemiology, diagnosis, and management. Clin Epidemiol. 2014; 6: 369-377. DOI: 10.2147/CLEP. S39981.

27. Utz J.P., Swensen, S.J., Gertz M.A. Pulmonary amyloidosis. The Mayo Clinic experience from 1980 to 1993. Ann. Inter. Med. 1996; 124 (4); 407-413.

28. Gillmore J.D., Hawkins P.N. Amyloidosis and the respiratory tract. Thorax. 1999; 54 (5): 444-451.

29. Kunze W.P. Senile pulmonary amyloidosis. Pathol. Res. Pract. 1979; 164 (4): 413-422.

30. Khoor A., Colby T.V. Amyloidosis of the lung. Arch. Pathol. Lab. Med. 2017; 141 (2): 247-254. DOI: 10.5858/arpa.20160102-ra.

31. Pitz M.W., Gibson I.W., Johnston J.B. Isolated pulmonary amyloidosis: Case report and review of the literature. Am. J. Hematol. 2006; 81 (3): 212-213. DOI: 10.1002/ajh.20518.

32. Grogg K.L., Aubry M.C., Vrana J.A. et al. Nodular pulmonary amyloidosis is characterized by localized immunoglobulin deposition and is frequently associated with an indolent B-cell lymphoproliferative disorder. Am. J. Surg. Pathol. 2013; 37 (3): 406-412. DOI: 10.1097/PAS.0b013e 318272fe 19.

33. Wang Q., Chen H., Wang S. Laryngo-tracheobronchial amyloidosis: a case report and review of literature. Int. J. Clin. Exp. Pathol. 2014; 7 (10): 7088-7093. 
34. Geusens E.A, Verschakelen J.A, Bogaert J.G. Primary pulmonary amyloidosis as a cause of interlobular septal thickening. Am. J. Roentgenol. 1997; 168: 116-117.

35. Vieira I.G., Marchiori E., Zanetti G. et al. Pulmonary amyloidosis with calcified nodules and masses-a six-year computed tomography follow-up: a case report. Cases J. 2009; 2 (1): 6540. DOI: 10.4076/1757-1626-2-6540.

36. Bril A.K., Woelke K., Schädlich R. et al. Tracheobronchial amyloidosis bronchoscopic diagnosis and therapy of an uncommon disease: a case report. J. Physiol. Pharmacol. 2007; 58 (Suppl. 5, Pt 1): 51-55.

37. Kırbaş G., Dağlı C.E., Tanrıkulu A.Ç. et al. Unusual combination of tracheobronchopathia osteochondroplastica and AA amyloidosis. Yonsei Med. J. 2009; 50 (5): 721-724. DOI: 10.3349/ymj.2009.50.5.721.

38. Naef A.P., Savary M., Grüneck J.S. et al. Amyloid pseudotumor treated by tracheal resection. Ann. Thorac. Surg. 1977; 23 (6): 578-581.

39. Berk J.L., O'Regan A., Skinner M. Pulmonary and tracheobronchial amyloidosis. Semin. Respir. Crit. Care Med. 2002; 23 (2): 155-165. DOI: 10.1055/s-2002-25304.

40. Road J.D., Jacques J., Sparling J.R. Diffuse alveolar septal amyloidosis presenting with recurrent hemoptysis and medial dissection of pulmonary arteries. Am. Rev. Respir. Dis. 1985; 132 (6): 1368-1370.

41. Streeten E.A., de la Monte S.M., Kennedy T.P. Amyloid infiltration of the diaphragm as a cause of respiratory failure. Chest. 1986; 89 (5): 760-762.

42. Chu H., Zhao L., Zhang Z. et al. Clinical characteristics of amyloidosis with isolated respiratory system involvement: a review of 13 cases. Ann. Thorac. Med. 2012; 7 (4): 243-249. DOI: $10.4103 / 1817-1737.102186$.

43. Howie A.J., Owen-Casey M.P. Discrepancies between descriptions and illustrations of colours in Congo redstained amyloid, and explanation of discrepant colours. Amyloid. 2010; 17 (3-4): 109-117. DOI: 10.3109/13506129. 2010.527448 .

Поступила 07.12.17

\section{References}

1. Rameev V.V., Kozlovskaya L.V. Amyloidosis: Current methods for diagnosis and treatment. Effektivnaya farmakoterapiya. 2012; (44): 6-15 (in Russian).

2. Pinney J.H., Smith C.J., Taube J.B. et al. Systemic amyloidosis in England: an epidemiological study. Br. J. Haematol. 2013; 161 (4): 525-532. DOI: 10.1111/bjh.12286.

3. Лысенко Л.В., Рамеев В.В. Национальные клинические рекомендации «Диагностика и лечение АAи AL-амилоидоза». М.; 2014. Доступно на: https://freedocs.xyz/view-docs.php?pdf=456688967

4. Urban B.A., Fishman E.K., Goldman S.M. et al. CT evaluation of amyloidosis: spectrum of disease. Radiographics. 1993; 13 (6): 1295-1308. DOI: 10.1148/radiographics. 13.6.8290725.

5. Brown K., Mund D.F., Aberle D.R. et al. Intrathoracic calcifications: radiographic features and differential diagnoses. Radiographics. 1994; 14 (6): 1247-1261. DOI: 10.1148/radiographics.14.6.7855339.

6. Smith R.R., Hutchins G.M., Moore G.W., Humphrey R.L. Type and distribution of pulmonary parenchymal and vascular amyloid. Correlation with cardiac amyloidosis. Am. J. Med. 1979; 66 (1): 96-104. DOI: 10.1016/0002-9343(79) 90488-1.

7. Scala R., Maccari U., Madioni C. et al. Amyloidosis involving the respiratory system: 5-ear's experience of a multi-dis- ciplinary group's activity. Ann. Thorac. Med. 2015; 10 (3): 212-216. DOI: 10.4103/1817-1737.157290.

8. Sipe J.D., Benson M.D., Buxbaum J.N. et al. Amyloid fibril proteins and amyloidosis: chemical identification and clinical classification International Society of Amyloidosis 2016 Nomenclature Guidelines. Amyloid. 2016; 23 (4): 209-213. DOI: $10.1080 / 13506129.2016 .1257986$.

9. Mukhin N.A., ed. Nephrology. National Guideline. Moscow: GEOTAR-Media; 2009 (in Russian).

10. Merlini G., Westermark P. The systemic amyloidoses: clearer understanding of the molecular mechanisms offers hope for more effective therapies. J. Int. Med. 2004; 255 (2): 159-178. DOI: 10.1046/j.1365-2796.2003.01262.x.

11. Merlini G., Seldin D.C., Gertz M.A. Amyloidosis: pathogenesis and new therapeutic options. J. Clin. Oncol. 2011; 29 (14): 1924-1933. DOI: 10.1200/jco.2010.32.2271.

12. Thompson P.J., Citron K.M. Amyloid and lower respiratory the tract. Thorax. 1983; 38 (2): 84-87.

13. Hui A.N., Koss M.N., Hochholzer L., Wehunt W.D. Amyloidosis presenting in the lower respiratory tract. Clinicopathologic, radiologic, immunohistochemical, and histochemical studies on 48 cases. Arch. Pathol. Lab. Med. 1986; 110 (3): 212-218.

14. Müller A.M., Geibel A., Neumann H.P.H. et al. Primary (AL) amyloidosis in plasma cell disorders. Oncologist. 2006; 11 (7): 824-830. DOI: 10.1634/theoncologist.11-7-824.

15. Bahlis N.J., Lazarus H.M. Multiple myeloma-associated AL amyloidosis: is a distinctive therapeutic approach warranted? Bone Marrow Transplant. 2006; 38 (1): 7-15. DOI: 10.1038/sj.bmt.1705395.

16. Dinner S., Witteles W., Witteles R. et al. The prognostic value of diagnosing concurrent multiple myeloma in immunoglobulin light chain amyloidosis. Br. J. Haematol. 2013; 161 (3): 367-372. DOI: 10.1111/bjh.12269.

17. Falk R.H. AL amyloidosis or multiple myeloma? An important distinction. Br. J. Haematol. 2014; 164 (5): 748-749. DOI: $10.1111 /$ bjh.12677.

18. Merlini G., Palladini G. Differential diagnosis of monoclonal gammopathy of undetermined significance. Hematology Am. Soc. Hematol. Educ. Program. 2012; 2012: 595-603. DOI: 10.1182/asheducation-2012.1.595.

19. Kyle R.A., Therneau T.M., Rajkumar S.V. et al. Long-term follow-up of 241 patients with monoclonal gammopathy of undetermined significance: the original Mayo Clinic series 25 years later. Mayo Clin. Proc. 2004; 79 (7): 859-866. DOI: 10.4065/79.7.859.

20. Kyle R.A., Therneau T.M., Rajkumar S.V. et al. A longterm study of prognosis in monoclonal gammopathy of undetermined significance. N. Eng. J. Med. 2002; 346 (8): 564-569. DOI: 10.1056/nejmoa01133202.

21. Warsame R., Kumar S.K., Gertz M.A. et al. Abnormal FISH in patients with immunoglobulin light chain amyloidosis is a risk factor for cardiac involvement and for death. Blood Cancer J. 2015; 5: e310. DOI: 10.1038/bcj.2015.34.

22. Suzuki K. Diagnosis and treatment of multiple myeloma and AL amyloidosis with focus on improvement of renal lesion. Clin. Exp. Nephrol. 2012; 16 (5): 659-671. DOI: 10.1007/s10157-012-0684-5.

23. Ramirez-Alvarado M., Ward C.J., Huang B.Q. et al. Differences in immunoglobulin light chain species found in urinary exosomes in light chain amyloidosis (Al). PLoS One. 2012; 7 (6): e38061. DOI: 10.1371/journal.pone.0038061.

24. Comenzo R.L., Zhang Y., Martinez C. et al. The tropism of organ involvement in primary systemic amyloidosis: contributions of $\operatorname{Ig~V(L)~germ~line~gene~use~and~clonal~plasma~cell~}$ 
burden. Blood. 2001; 98 (3): 714-720. DOI: 10.1182/blood. v98.3.714.

25. Perfetti V., Casarini S., Palladini G. et al. Analysis of $\mathrm{V} \lambda-\mathrm{J} \lambda$ expression in plasma cells from primary (AL) amyloidosis and normal bone marrow identifies $3 \mathrm{r}(\lambda \mathrm{III})$ as a new amyloid-associated germline gene segment. Blood. 2002; 100 (3): 948-953. DOI: 10.1182/blood-2002-01-0114.

26. Real de Asúa D., Costa R., Galván J.M. et al. Systemic AA amyloidosis: epidemiology, diagnosis, and management. Clin Epidemiol. 2014; 6: 369-377. DOI: 10.2147/CLEP. S39981.

27. Utz J.P., Swensen, S.J., Gertz M.A. Pulmonary amyloidosis. The Mayo Clinic experience from 1980 to 1993. Ann. Inter. Med. 1996; 124 (4); 407-413.

28. Gillmore J.D., Hawkins P.N. Amyloidosis and the respiratory tract. Thorax. 1999; 54 (5): 444-451.

29. Kunze W.P. Senile pulmonary amyloidosis. Pathol. Res. Pract. 1979; 164 (4): 413-422.

30. Khoor A., Colby T.V. Amyloidosis of the lung. Arch. Pathol. Lab. Med. 2017; 141 (2): 247-254. DOI: 10.5858/arpa.20160102-ra.

31. Pitz M.W., Gibson I.W., Johnston J.B. Isolated pulmonary amyloidosis: Case report and review of the literature. Am. J. Hematol. 2006; 81 (3): 212-213. DOI: 10.1002/ajh.20518.

32. Grogg K.L., Aubry M.C., Vrana J.A. et al. Nodular pulmonary amyloidosis is characterized by localized immunoglobulin deposition and is frequently associated with an indolent B-cell lymphoproliferative disorder. Am. J. Surg. Pathol. 2013; 37 (3): 406-412. DOI: 10.1097/PAS. 0b013 e318272fe19.

33. Wang Q., Chen H., Wang S. Laryngo-tracheobronchial amyloidosis: a case report and review of literature. Int. J. Clin. Exp. Pathol. 2014; 7 (10): 7088-7093.

34. Geusens E.A, Verschakelen J.A, Bogaert J.G. Primary pulmonary amyloidosis as a cause of interlobular septal thickening. Am. J. Roentgenol. 1997; 168: 116-117.
35. Vieira I.G., Marchiori E., Zanetti G. et al. Pulmonary amyloidosis with calcified nodules and masses-a six-year computed tomography follow-up: a case report. Cases J. 2009; 2 (1): 6540. DOI: 10.4076/1757-1626-2-6540.

36. Bril A.K., Woelke K., Schädlich R. et al. Tracheobronchial amyloidosis bronchoscopic diagnosis and therapy of an uncommon disease: a case report. J. Physiol. Pharmacol. 2007; 58 (Suppl. 5, Pt 1): 51-55.

37. Kırbaş G., Dağlı C.E., Tanrıkulu A.Ç. et al. Unusual combination of tracheobronchopathia osteochondroplastica and AA amyloidosis. Yonsei Med. J. 2009; 50 (5): 721-724. DOI: 10.3349/ymj.2009.50.5.721.

38. Naef A.P., Savary M., Grüneck J.S. et al. Amyloid pseudotumor treated by tracheal resection. Ann. Thorac. Surg. 1977; 23 (6): $578-581$.

39. Berk J.L., O’Regan A., Skinner M. Pulmonary and tracheobronchial amyloidosis. Semin. Respir. Crit. Care Med. 2002; 23 (2): 155-165. DOI: 10.1055/s-2002-25304.

40. Road J.D., Jacques J., Sparling J.R. Diffuse alveolar septal amyloidosis presenting with recurrent hemoptysis and medial dissection of pulmonary arteries. Am. Rev. Respir. Dis. 1985; 132 (6): 1368-1370.

41. Streeten E.A., de la Monte S.M., Kennedy T.P. Amyloid infiltration of the diaphragm as a cause of respiratory failure. Chest. 1986; 89 (5): 760-762.

42. Chu H., Zhao L., Zhang Z. et al. Clinical characteristics of amyloidosis with isolated respiratory system involvement: a review of 13 cases. Ann. Thorac. Med. 2012; 7 (4): 243-249. DOI: 10.4103/1817-1737.102186.

43. Howie A.J., Owen-Casey M.P. Discrepancies between descriptions and illustrations of colours in Congo redstained amyloid, and explanation of discrepant colours. Amyloid. 2010; 17 (3-4): 109-117. DOI: 10.3109/13506129. 2010.527448 .

Received December 07, 2017 